\title{
Porcine liver vascular bed in Biodur E20 corrosion casts
}

L. Eberlova1, 2, V. Liska2, 3, H. Mirka2, 4, T. Gregor ${ }^{5}$, Z. Tonar6, R. Palek², 3, M. Skala2, 3 , J. Bruha'2, 3, O. Vycital2, 3, K. Kalusova1', S. Haviar7, M. Kralickova², 8, A. Lametschwandtner ${ }^{9}$

${ }^{1}$ Department of Anatomy, Faculty of Medicine in Pilsen, Charles University in Prague, Pilsen, Czech Republic ${ }^{2}$ Biomedical Centre, Faculty of Medicine in Pilsen, Charles University in Prague, Pilsen, Czech Republic ${ }^{3}$ Department of Surgery, Charles University Prague, University Hospital in Pilsen, Pilsen, Czech Republic ${ }^{4}$ Department of Imaging Methods, Faculty of Medicine in Pilsen, Charles University in Prague, Faculty Hospital in Pilsen, Pilsen, Czech Republic

${ }^{5}$ New Technologies - Research Centre, University of West Bohemia, Pilsen, Czech Republic ${ }^{6}$ European Centre of Excellence NTIS, University of West Bohemia, Plzen, Czech Republic

${ }^{7}$ Department of Physics and NTIS - European Centre of Excellence, University of West Bohemia, Plzen, Czech Republic ${ }^{8}$ Department of Histology and Embryology, Faculty of Medicine in Pilsen, Charles University in Prague, Pilsen, Czech Republic ${ }^{9}$ Department of Cell Biology, University Salzburg, Salzburg, Austria

[Received: 20 June 2015; Accepted: 16 September 2015]

Background: Pigs are frequently used as animal models in experimental medicine. To identify processes of vascular development or regression, vascular elements must be recognised and quantified in a three-dimensional (3D) arrangement. Vascular corrosion casts enable the creation of 3D replicas of vascular trees. The aim of our study was to identify suitable casting media and optimise the protocol for porcine liver vascular corrosion casting.

Materials and methods: Mercox $\|^{\circledR}$ (Ladd Research, Williston, Vermont, USA) and Biodur E2 ${ }^{\circledR}$ Plus (Biodur Products, Heidelberg, Germany) were tested in 4 porcine livers. The resins (volume approximately $700 \mathrm{~mL}$ ) were injected via the portal vein. Corrosion casts were examined by macro-computed tomography, micro-computed tomography and scanning electron microscopy.

Results: For hepatectomies, the operating protocol was optimised to avoid gas or blood clot embolisation. We present a protocol for porcine liver vascular bed casting based on corrosion specimens prepared using Biodur $E 20^{\circledR}$ epoxy resin. Conclusions: Only Biodur E20 ${ }^{\circledR}$ Plus appeared to be suitable for high-volume vascular corrosion casting due to its optimal permeability, sufficient processing time and minimum fragility. Biodur E20 ${ }^{\circledR}$ Plus is slightly elastic, radio-opaque and alcohol-resistant. These properties make this acrylic resin suitable for not only vascular research but also teaching purposes. (Folia Morphol 2016; 75, 2: 154-161)

Key words: porcine liver, vascular corrosion cast, Biodur E20, micro-computed tomography, scanning electron microscopy

\section{INTRODUCTION}

Because the anatomical, genetic and physiological characteristics of pigs are similar to those of humans [33], pigs are frequently used as animal models in experimental medicine. The liver parenchyma has the unique ability to regenerate [14]. Its functional capacity is dependent on establishing new microcirculation [9]. Detailed anatomical 
Table 1. Mammalian liver vascular corrosion casts — review, animals arranged in alphabetical order

\begin{tabular}{|c|c|c|c|c|c|}
\hline Animal & Resin & Injected by & $\begin{array}{l}\text { Pressure } \\
\text { monitored }\end{array}$ & $\begin{array}{l}\text { Micro-vasculature } \\
\text { filled }\end{array}$ & Reference \\
\hline Cow & $\begin{array}{l}\text { Dental acron*, Technovit } \\
\text { (Heraeus Kulzer, Hanau, } \\
\text { Germany) }\end{array}$ & $\begin{array}{l}\text { PV, HA, hepatic veins, } \\
\text { hepatic ducts }\end{array}$ & * & No & [30] \\
\hline \multirow[t]{2}{*}{ Dog } & $\begin{array}{l}\text { Polirepar S (Polident, Dental } \\
\text { Products Industry, Slovenia) }\end{array}$ & $\begin{array}{l}\text { PV, HA, CCV, } \\
\text { bile duct }\end{array}$ & $\begin{array}{c}\text { No } \\
\text { (manual injection) }\end{array}$ & No & [32] \\
\hline & $\begin{array}{l}\text { Epoxy resin*, polymerising } \\
\text { agent Araldite }{ }^{\mathrm{ND} *}\end{array}$ & PV & * & No & [26] \\
\hline \multirow[t]{3}{*}{ Human } & $\begin{array}{l}\text { Batson's \#17 (Polysciences, } \\
\text { Warrington, USA) }\end{array}$ & $\mathrm{PV}, \mathrm{HA}$ & Yes & Yes & {$[5-7]$} \\
\hline & $\begin{array}{l}\text { Polirepar S (Polident, } \\
\text { Volčja draga, Slovenia) }\end{array}$ & $\begin{array}{l}\text { PV, HA, hepatic ducts, } \\
\text { vena cava inferior }\end{array}$ & $\begin{array}{c}\text { No } \\
\text { (manual injection) }\end{array}$ & No & [4] \\
\hline & $\begin{array}{l}\text { Mercox (Oken-Shoji, } \\
\text { Tokyo, Japan) }\end{array}$ & PV, HA & $*$ & Yes & [28] \\
\hline Mouse embryo & Mercox (Dainnipon Ink Co.) & Umbilical vessel $^{*}$ & Yes & Yes & [16] \\
\hline Monkey & $\begin{array}{l}\text { Mercox (Oken-Shoji, } \\
\text { Tokyo, Japan) }\end{array}$ & Thoracic aorta & * & Yes & [28] \\
\hline Pig & $\begin{array}{l}\text { Technovit } 7143 \text { (Heraeus, } \\
\text { Germany) }\end{array}$ & PV & $*$ & No & [23] \\
\hline Rabbit & $\begin{array}{l}\text { Mercox (Oken-Shoji, } \\
\text { Tokyo, Japan) }\end{array}$ & Thoracic aorta & * & Yes & [28] \\
\hline \multirow[t]{2}{*}{ Rat } & $\begin{array}{l}\text { Mercox CL2 R (Okenshoji, } \\
\text { Tokyo, Japan) }\end{array}$ & Ascending aorta & Yes & Yes & [10] \\
\hline & $\begin{array}{l}\text { Mercox (Oken-Shoji, } \\
\text { Tokyo, Japan) }\end{array}$ & Thoracic aorta & $*$ & Yes & [28] \\
\hline Ship & $\begin{array}{l}\text { Interacryl cold (Interdent, } \\
\text { Gornji Grad, Slovenia) }\end{array}$ & $\begin{array}{c}\text { PV, HA, } \\
\text { hepatic veins }\end{array}$ & * & No & [12] \\
\hline
\end{tabular}

${ }^{*}$ Not specified; CCV — caudal caval vein; HA — hepatic artery; PV — portal vein

data for the liver microvasculature are required to identify processes of vascular development or regression [17], for quantitative analysis [18, 19, 31] or for blood-flow modelling $[5,29]$. Vascular corrosion casts enable the creation of three-dimensional (3D) replicas of vascular trees.

The liver has a unique blood flow pattern. There are two inputs: the portal vein (PV) and the hepatic artery (HA). The PV transmits nutrient-rich, less oxygenated, low-pressure blood from unpaired organs in the abdomen. The HA inflow is the second, smaller (approximately 30\%) input for the liver and conveys oxygenated blood. The PV and HA enter the porta hepatis, they divide into the right and left branches and subsequently the segmental and subsegmental branches. The arterial branches invariably follow those of the PV [3]. Their terminal branches end in the hepatic sinusoids and the peribiliary and periportal plexuses, which open into the portal vein or hepatic sinusoids [28]. The interlobular (collecting) branches of the portal vein continue into the circumlobular (distributing) branches and hepatic sinusoids $[8,15]$. Blood from the sinusoids enters the hepatic veins via the central veins. The hepatic veins drain into the caudal caval vein (CCV). This complicated liver vasculature makes liver corrosion casting challenging, particularly in larger animals. The porcine liver microvasculature has not yet been studied from this perspective (Table 1). The aim of our study was to identify suitable casting media and optimise the protocol for porcine liver vascular corrosion casting.

\section{MATERIALS AND METHODS}

For the corrosion casting of livers, 4 Sus scrofa f. domestica piglets (age $42-70$ days, weight $12-25 \mathrm{~kg}$ ) were operated on under general anaesthesia. 


\section{Casting protocol}

Casting protocol including: hepatectomy, casting media dilution and resin injection, polymerisation and maceration.

Hepatectomy. The piglets were premedicated intramuscularly with atropine $1.0 \mathrm{mg}$, ketamine $200 \mathrm{mg}$ (approximately 5-10 mg/kg) and azaperon $160 \mathrm{mg}$ $(2-8 \mathrm{mg} / \mathrm{kg})$. Anaesthesia was administered continuously through a peripheral or central venous catheter at the following total average doses: propofol (1\% mixture $5-10 \mathrm{mg} / \mathrm{kg} / \mathrm{h})$ and fentanyl $(1-2 \mu \mathrm{g} /$ $/ \mathrm{kg} / \mathrm{h}$ ). Muscle relaxation was ensured by bolus administration of pancuronium $0.1-0.2 \mathrm{mg} / \mathrm{kg}$ at the beginning of the surgery. The piglets were intubated and mechanically ventilated during the surgical procedure and received infusions and volume substitutions when necessary (Plasmalyte Baxter and Gelofusine B-Braun, respectively). Electrocardiogram, oxygen saturation and central venous pressure were monitored during surgery. The surgical procedure was performed under aseptic and antiseptic conditions. To maintain free macro- and micro-circulation to fill the entire vascular bed, heparin (30,000 UI i.v.) was administered. Before hepatectomy, the vascular tree was flushed with $5 \mathrm{~L}$ of heparinised solution (dilution: 10,000 UI of heparin per $1 \mathrm{~L}$ of Hartmann's solution) via the caudal caval vein. To prevent gas emboli, the HA, PV, hepatic ducts and CCV were cut under water niveau. After washing, the liver vascular system was again clamped. The piglets were sacrificed at the end of the operation under deep general anaesthesia with a concentrated solution of potassium chloride administered into a central vein.

The experimental surgical and anaesthesiological procedures and the use of piglets in this study were certified by the Commission for Work with Experimental Animals at the Pilsen Medical Faculty of Charles University, Prague and were under the control of the Ministry of Agriculture of the Czech Republic. All procedures were prepared and performed under the law of the Czech Republic, which is compatible with the legislation of the European Union.

Casting media. For porcine livers of animals weighing less than $30 \mathrm{~kg}, 500-700 \mathrm{~mL}$ of resin appeared to be satisfactory. The injection volume of the resin is dependent on the size of the liver. Leakage of the resin from the CCV indicated that the liver was adequately filled. Because polymerisation begins as soon as the resin is mixed with the catalyst, all preparations involving the application of the resin must be completed prior to mixing.

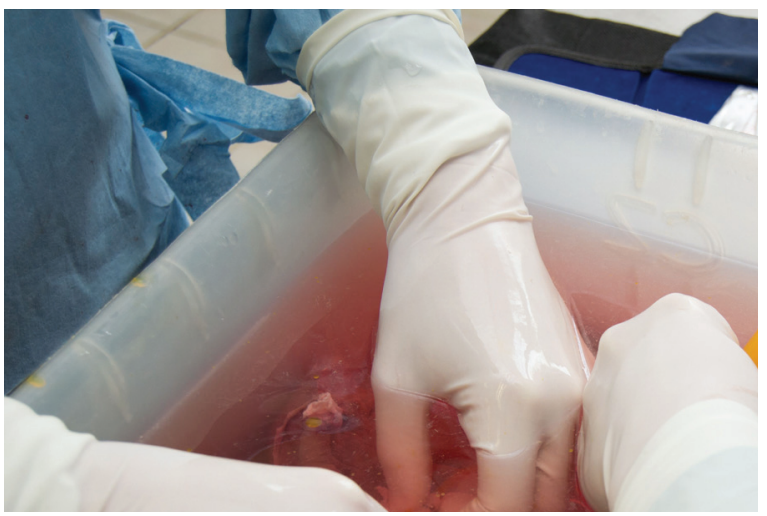

Figure 1. Yellow-dyed Biodur $E 20^{\circledR}$ Plus manual injection into the portal vein under water niveau.

Mercox $\|^{\circledR}$ (Ladd Research, Williston, Vermont, USA): $400 \mathrm{~mL}$ of Mercox II was mixed with $9 \mathrm{~g}$ of catalyst ( $40 \%$ benzoyl peroxide).

Biodur E20 ${ }^{\circledR}$ Plus (Biodur Products, Heidelberg, Germany): $400 \mathrm{~g}$ of Biodur E20 Plus was mixed with $180 \mathrm{~g}$ of catalyst E2(0).

Direct contact with the highly toxic chemicals was avoided by working in a ventilated room and wearing protective gloves, glasses and respiratory filters.

Resin injection, polymerisation and maceration. To prevent artefact formation during hardening, the liver was positioned upwards with the diaphragmatic surface placed in a container filled with lukewarm tap water. To avoid air embolisation, all of the procedures were performed under the surface of the water. After releasing all vessel ligations, resin was injected under manual pressure (flow rate $150 \mathrm{~mL} / \mathrm{min}$ ) into the portal vein via a Nelaton catheter (Fig. 1). Once resin began leaking from the caudal caval vein, the PV, HA and inferior vena cava were clamped. Then, the liver was stored in the water and allowed to polymerise at room temperature for the next $24 \mathrm{~h}$. The liver was then macerated for 3 days at room temperature in a $15 \%$ potassium hydroxide solution, and the cast was rinsed in tap water. The whole-liver casts were preserved in $90 \%$ alcohol.

\section{Computed tomography (CT) scanning and data processing}

1. The casts were first scanned in $90 \%$ alcohol using a multi-slice human CT (Somatom Sensation 64, Siemens, Forchheim, Germany) with a slice thickness of $0.6 \mathrm{~mm}$ and voxel size of $0.4 \times 0.4 \times$ $\times 0.6 \mathrm{~mm}$. 

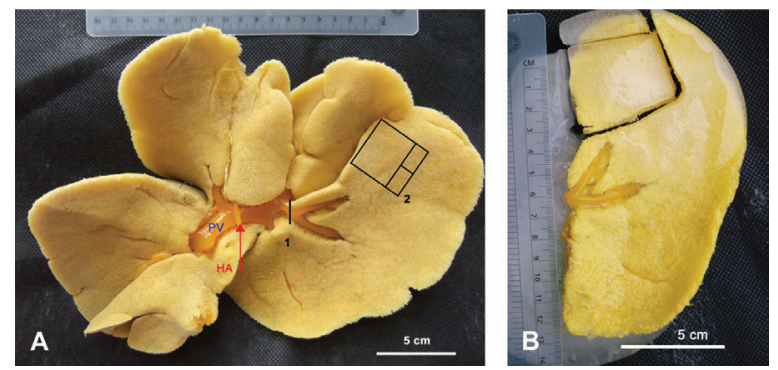

Figure 2. A. Porcine liver vascular corrosion cast, visceral surface, portal filling with yellow-dyed Biodur E20 ${ }^{\circledR}$ Plus (Biodur products, Heidelberg, Germany); PV — portal vein; HA — hepatic artery proper; B. Left lateral lobe - segmentation in an ice prism.

2. To perform high-resolution scanning, the casts were cut into small prisms (Fig. 2). The following sampling pattern was used: Each lobe was separated, rinsed of alcohol and frozen in distilled water, and prisms approximately $2 \times 1 \times 1 \mathrm{~cm}$ in size (Table 2 ) were randomly cut with a belt saw. Randomly chosen samples underwent micro-CT examination.

3. The microarchitecture of the liver vessels at the level of the sinusoids was scanned in air using a micro-CT (Xradia XCT 400, Pleasanton, CA, USA). The pixel sizes used for imaging were $17 \mu \mathrm{m}$, $9.5 \mu \mathrm{m}$ and $4.5 \mu \mathrm{m}$. The architecture of the liver vessels at the level of the sinusoids was visualised using a volume rendering technique and thin-slab maximum intensity projection.

\section{Scanning electron microscopy (SEM)}

The remaining cut lobes were placed into distilled water. They were frozen and cut with a belt saw into prisms approximately $1 \times 1 \times 0.5 \mathrm{~cm}$ in size. Specimens were cleaned in $5 \%$ formic acid for $20 \mathrm{~min}$, rinsed in distilled water and re-frozen. After freeze-drying, the specimens were mounted on copper foils and fixed using wire stubs with conductive silver paste according to a method described by Lametschwandtner et al. [21]. Then, the specimens were sputtered with gold for $60 \mathrm{~s}$ and examined using a Stereoscan 250 SEM (Cambridge, UK) at an accelerating voltage of $10 \mathrm{kV}$. Preliminary imaging was performed with an SEM SU-70 (Hitachi, Japan) using an accelerating voltage of $1 \mathrm{kV}$ because this protocol does not require any pretreatment of specimens.

\section{RESULTS}

The differences between the two resins tested are summarised in Table 3. Mercox $\|^{\circledR}$ (Ladd Research, Williston, Vermont, USA) did not appear to be suitable for casting volumes greater than $400 \mathrm{~mL}$. The main disadvantage was the highly variable, short working time, which is dependent on the quantity of resin and storage. For greater quantities, the working time rapidly decreases, and mixing produces a considerably exothermic reaction.

However, in all three liver casts, Biodur E2 ${ }^{\circledR}$ Plus (Biodur Products, Heidelberg, Germany) passed through the portal venous bed and also filled the sinusoids and hepatic venous system (Figs. 3, 4). In the smallest liver, the HA proper was also retrogradely filled (Fig. 2A). Due to its chemical and rheological properties, Biodur E2 ${ }^{\circledR}$ Plus was thus suitable for large-volume corrosion casting and provided good replication quality (Fig. 4C). In macro-CT, the software packages permitted the separation of the caval from the portal systems (Fig. 5). The radio-opacity of Biodur $\mathrm{E} 20^{\circledR}$ Plus also permits its use for high-resolution CT imaging (Fig. 3).

In all casts and samples, we observed globular structures (Fig. 3) in course of sinusoids that appeared under SEM to be resin extravasations (Fig. 4D).

\section{DISCUSSION}

To obtain the highest authenticity 3D vascular bed in corrosion casts, careful preparation, specific anaesthesia and irrigation of the arterio-venous tree

Table 2. Review of Biodur E20 ${ }^{\circledR}$ Plus porcine liver samples examined

\begin{tabular}{|c|c|c|c|c|}
\hline Liver & Weight of pig & Lobe cut & $\begin{array}{c}\text { Micro-CT } \\
2 \times 1 \times 1 \mathrm{~cm} \\
\end{array}$ & $\begin{array}{c}\text { SEM } \\
1 \times 1 \times 0.5 \mathrm{~cm} \\
\end{array}$ \\
\hline \multirow[t]{2}{*}{ No. 1} & $12 \mathrm{~kg}$ & Left lateral lobe & 2 & 2 \\
\hline & & Right medial lobe & 2 & 2 \\
\hline No. 2 & $27 \mathrm{~kg}$ & Right lateral lobe & 3 & 4 \\
\hline №. 3 & $25 \mathrm{~kg}$ & Right lateral lobe & 3 & 4 \\
\hline
\end{tabular}

CT — computed tomography; SEM — scanning electron microscopy 
Table 3. Resins tested

\begin{tabular}{|c|c|c|c|c|c|c|}
\hline \multirow{2}{*}{$\begin{array}{l}\text { Name of resin, } \\
\text { producer }\end{array}$} & \multirow{2}{*}{$\begin{array}{c}\text { Number } \\
\text { of whole } \\
\text { liver casts }\end{array}$} & \multirow{2}{*}{$\begin{array}{c}\text { Chemical } \\
\text { nature } \\
\text { of resin }\end{array}$} & \multicolumn{2}{|c|}{ Dilution used } & \multirow{2}{*}{$\begin{array}{c}\text { Working } \\
\text { time }\end{array}$} & \multirow[t]{2}{*}{ Other properties } \\
\hline & & & Resin & Catalyst & & \\
\hline $\begin{array}{l}\text { Mercox } \|^{\circledR} \\
\text { Ladd Research, } \\
\text { Williston, Vermont, } \\
\text { USA }\end{array}$ & 1 & Acrylic & $\begin{array}{l}400 \mathrm{~mL} \text { of } \\
\text { Mercox } \|^{\circledR}\end{array}$ & $9 \mathrm{~g}$ & $\begin{array}{l}5 \min \\
(\max .)\end{array}$ & $\begin{array}{c}\text { Advantages: sufficient radio- } \\
\text {-opacity for micro-computed } \\
\text { tomography imaging (Fig. 6) } \\
\text { Disadvantages: a short, variable } \\
\text { working time; a maximum } \\
\text { appropriate mixing volume } \\
\text { of only } 20 \mathrm{~mL} \text {; very fragile, } \\
\text { difficult-to-cut cured product. } \\
\text { Casts must not be preserved } \\
\text { in alcohol! }\end{array}$ \\
\hline $\begin{array}{l}\text { Biodur E20 }{ }^{\circledR} \text { Plus } \\
\text { Biodur Products, } \\
\text { Heidelberg, Germany }\end{array}$ & 3 & Epoxide & $400 \mathrm{~g}$ of E20 & $180 \mathrm{~g}$ of E2(0) & $\begin{array}{l}40 \min \\
\text { (min.) }\end{array}$ & $\begin{array}{l}\text { Advantages: a long working } \\
\text { time; sufficient radio-opacity } \\
\text { (both the radio-opacity and the } \\
\text { processing can be increased by } \\
\text { commercially available Biodur } \\
\text { additives); low cost; alcohol } \\
\text { resistant; slightly flexible }\end{array}$ \\
\hline
\end{tabular}
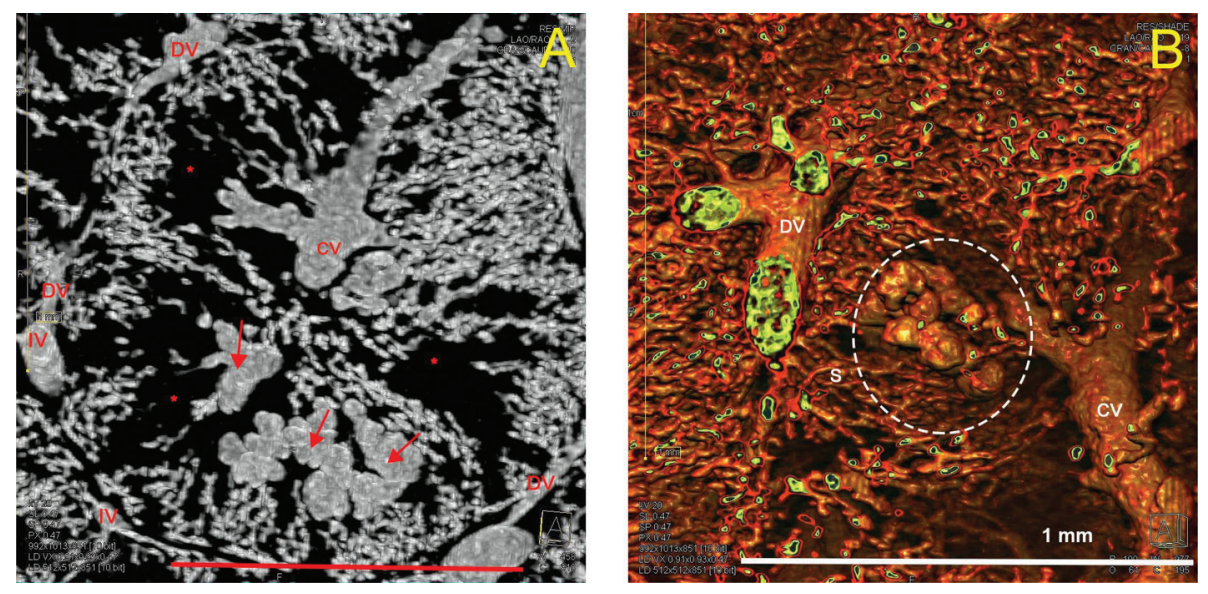

Figure 3. A. Porcine liver vascular corrosion cast, portal filling, Biodur $E 20^{\circledR}$ Plus, maximum intensity projection reconstruction; CV — central vein; DV — distributing portal vein; IV — interlobular (conducting) portal vein; S — sinusoid; arrow — resin extravasation; asterisk $\left(^{*}\right)$ incomplete sinusoidal filling; micro-computed tomography, bar $1 \mathrm{~mm}$; B. Porcine liver vascular corrosion cast, portal filling, Biodur E20 ${ }^{\circledR}$ Plus, volume rendering technique reconstruction; CV — central vein, DV — distributing (circumlobular) portal vein; S — sinusoid; circle — resin extravasation; micro-computed tomography.

are necessary. The choice of suitable casting material is determined by a variety of factors, such as the purpose of the final casts, cast size and the modality of subsequent examination. The casting medium should have adequate viscosity (to pass through but not penetrate), and sufficient working time is limiting, especially in large casts. Additionally, the casting material must be capable of even polymerisation with minimal shrinkage and physicochemically resistant to further corrosion, dissection and preservation procedures $[11,20]$.
The most commonly used resins (Table 1) are methyl methacrylates such as Mercox [2] or modified Batson's $17[5,6]$. Methyl methacrylates are generally capillary-passable and alcohol non-resistant. Their limitations are a relatively short working time and high fragility [11]. Biodur E20 is a translucent, firm epoxy resin of medium viscosity and slightly flexible consistency. It was used by Masset et al. [24] to reveal the angioarchitecture of equine periodontium. With the exception of shrinkage, which was not assessed in our study, Biodur E20 ${ }^{\circledR}$ Plus appeared to be suitable for large 

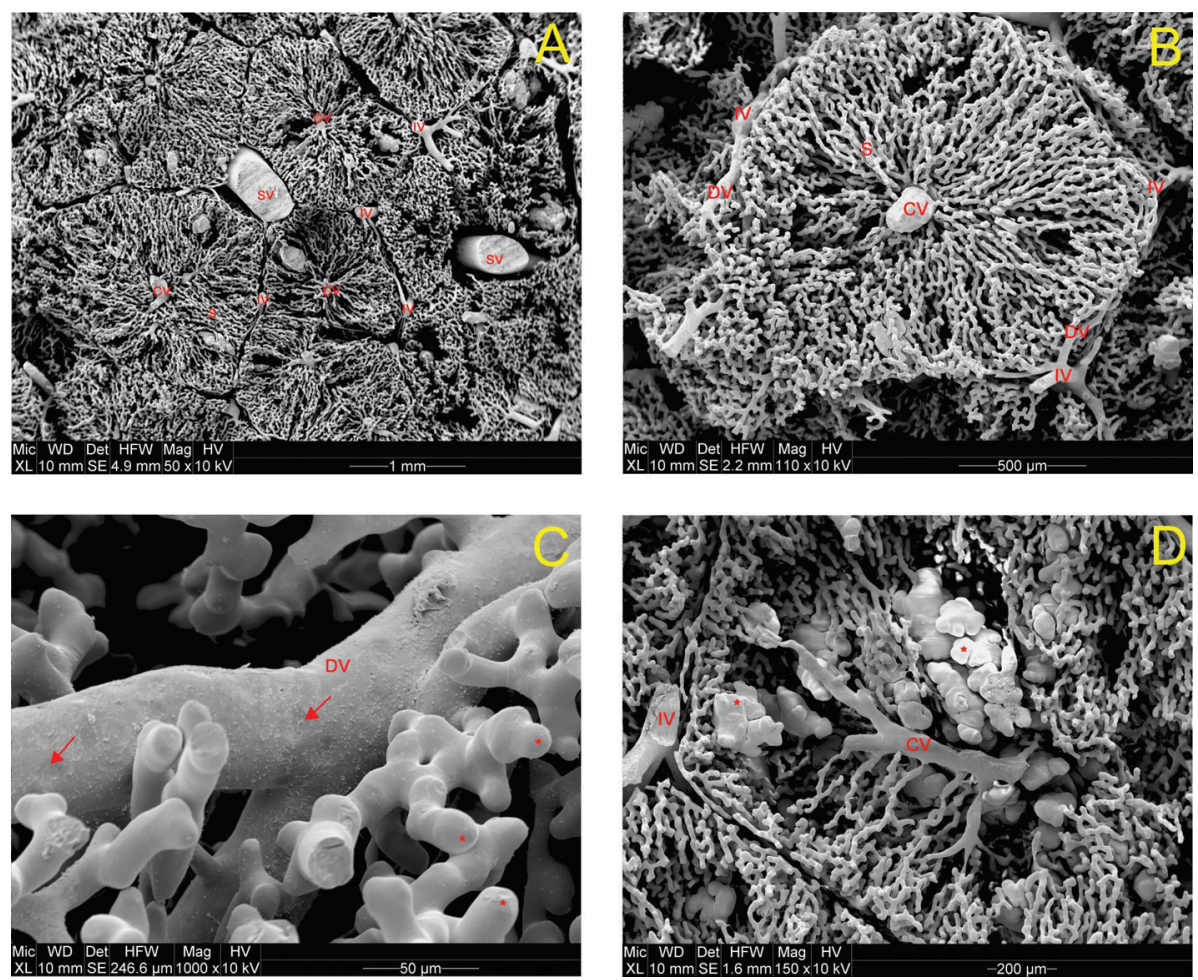

Figure 4. Porcine liver vascular corrosion cast, portal filling, Biodur E20 ${ }^{\circledR}$ Plus; scanning electron microscopy; A. CV — central vein; DV — distributing portal vein; IV — interlobular (conducting) portal vein; S — sinusoids; B. Hepatic lobule; CV — central vein; S — sinusoids; DV — distributing portal vein; IV — interlobular (conducting) portal vein; SEM; C. DV — distributing (circumlobular) portal vein; asterisk (*) — blindly ending sinusoids; arrow — imprints of endothelial cell nuclei; D. Hepatic lobule; CV — central vein; IV — interlobular (conducting) vein; asterisk $\left({ }^{*}\right)$ - resin extravasation.

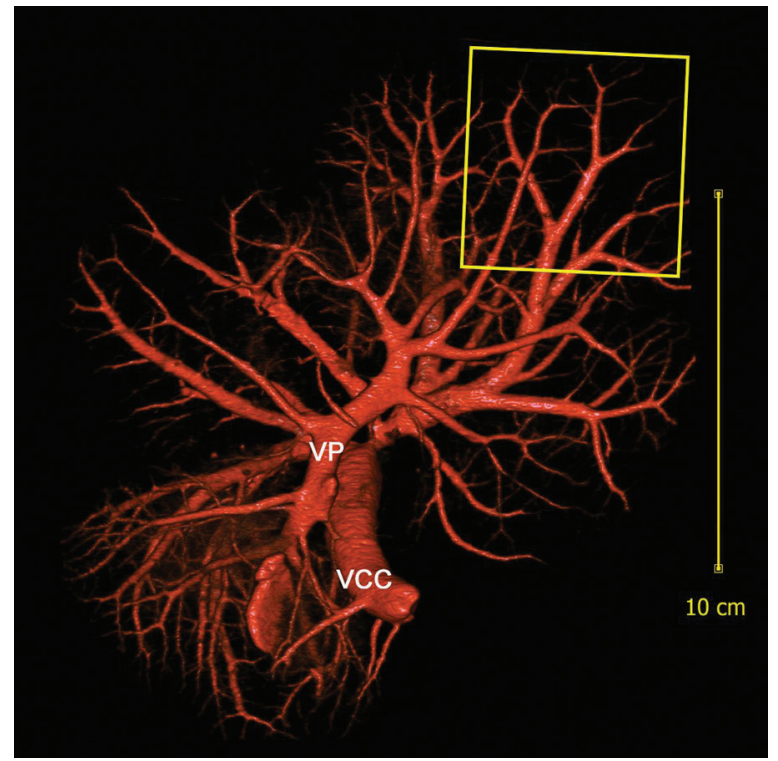

Figure 5. Porcine liver vascular corrosion cast, portal filling, Biodur E20 ${ }^{\circledR}$ Plus, volume rendering technique; VP — portal vein; VCC caudal caval vein, rectangle — cut part of the left lateral lobe; multi-slice human computed tomography.

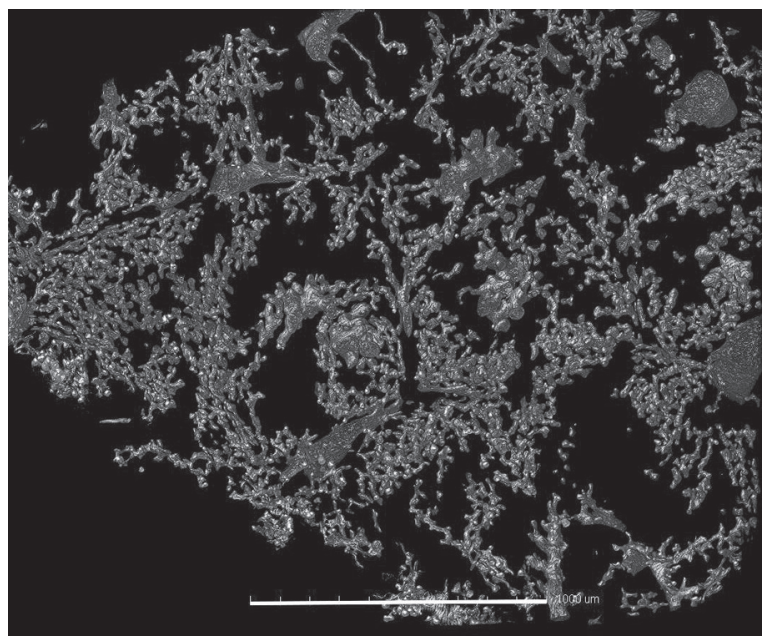

Figure 6. Porcine liver vascular corrosion cast, portal filling, MercoX II ${ }^{\circledR}$; micro-computed tomography, bar $1 \mathrm{~mm}$.

vascular corrosion casts. Although the resin was injected only via the portal vein, both micro-CT and SEM scans demonstrated that Biodur $E 20^{\circledR}$ Plus passed through the 
sinusoids and connected the portal and hepatic veins (Figs. 3, 4). However, the arterial beds with peribiliary plexuses [28] in the interlobular spaces were missing, and parts of the lobules and sinusoids were not completely filled (Figs. 3A, 4A, B). These absences might have been due to a contraction of inlet sphincters, by cells protruding into the sinusoidal lumen [25] or by the absence of pressure from the missing arterial inflow.

To our knowledge, a liver corrosion cast of a specimen weighing over $20 \mathrm{~kg}$ has not before been created (Table 1). The only exception is a human liver discarded for transplantation that was casted using Batson's 17 [6, 7]. Batson's 17 appeared to be suitable for CT scanning, but the quality of the microvessel bed replica has only been demonstrated on a small-volume sample.

In all of our samples (Table 2), the micro-CT scans revealed globular structures in the sinusoids, which could have been either tortuous sinusoids or artefacts (Fig. 3). SEM, which permits the identification of delicate structures such as vessel sphincters, valves, and nuclear imprints $[1,27]$, suggested that these grape-like structures were resin extravasations, i.e., artefacts (Fig. 4D). In our study, we did not monitor the pressure during injection because pressure does not correspond to the peripheral intraluminal pressure. Because of the size of the livers and the rheological properties of Biodur E2 ${ }^{\circledR}$ Plus at $20^{\circ} \mathrm{C}$ (kinematic viscosity $150-170 \mathrm{cST}$, density $1.1 \mathrm{~g} / \mathrm{cm}^{3}$ ), the extravasates were likely the result of local higher sinusoidal permeability because the liver sinusoids are lined by discontinuous endothelial cells with fenestrations and the basal lamina is missing [22]. The globular shape of the extravasates might be due to the hydrophobic nature of the epoxy resin as the space of Disse was filled with a water solution during the hepatectomy.

Except for a few organs [13], to make a microvascular corrosion cast, the entire, fresh organ must be available. This condition highlights the importance of our results, as pigs are frequently used as animal models in experimental medicine. In addition, the alcohol resistance of Biodur $E 20^{\circledR}$ Plus with the possibility of soft tissue preservation increases the potential of the application of casts made with this resin for not only research but also teaching purposes [11].

\section{CONCLUSIONS}

We present a protocol for porcine liver vascular bed casting based on corrosion specimens prepared using Biodur E20 ${ }^{\circledR}$ Plus epoxy resin (Biodur Products,
Heidelberg, Germany). Biodur E2 $0^{\circledR}$ Plus permeates throughout the entire microvascular bed and offers sufficient radio-opacity. The degree of elasticity of Biodur E2 $2^{\circledR}$ Plus permits safe cast handling as well as dissection, and the alcohol resistance of this resin is useful for the preservation of specimens both before and after corrosion. Macro- and micro-CT scans enabled 3D reconstruction of the entire vascular bed. The micro-CT images enabled stereological assessment. In combination with SEM, corrosion casting increases the possibility of morphometric analysis of a vascular network in health and disease. Our results can also be used to correlate 3D models with 2D liver histopathology or to provide data to optimise liver resections or perfusion models. Because pigs are frequently used as a surrogate animal model, our results can be used for not only morphological vascular research but also anatomy education.

\section{ACKNOWLEDGEMENTS}

This work was supported by the Internal Grant Agency of the Ministry of Health of the Czech Republic under Project No. IGA MZ ČR 13326, SVV No. 260 170, by the National Sustainability Program I (NPU I) No. L01503 provided by the Ministry of Education, Youth and Sports of the Czech Republic, by the CENTEM project reg. No. CZ.1.05/2.1.00/03.0088, and partly supported by the European Regional Development Fund under Project "NTIS - New Technologies for Information Society", European Centre of Excellence, CZ.1.05/1.1.00/02.0090. Z. Tonar was also supported by the project LO1506 of the Czech Ministry of Education, Youth and Sports.

A special thanks to the Austrian Agency for International Mobility and Cooperation in Education, Science and Research (OeAD) for awarding the Österreich-Tschechien Aktion scholarship. Many thanks also to $\mathrm{Dr}$. Örs Petnehazy, PhD, for sharing his valuable experience.

\section{REFERENCES}

1. Aharinejad SH, Lametschwandtner A (1992) Microvascular Corrosion Casting in Scanning Electrone Microscopy. Springer, Berlin-Heidelberg-Wien.

2. Bereza T, Tomaszewski KA, Lis GJ, Mizia E, Pasternak A, Mazur M, Mituś J (2014) 'Venous lakes' - a corrosion cast scanning electron microscopy study of regular and myomatous human uterine blood vessels. Folia Morphol, 73: 164-168. doi: 10.5603/FM.2014.0024.

3. Camprodon R, Solsona J, Guerrero JA, Mendoza CG, Segura J, Fabregat JM (1977) Intrahepatic vascular division in the pig: basis for partial hepatectomies. Arch Surg, 112: 38-40. 
4. De Cecchis L, Hribernik M, Ravnik D, Gadzijev EM (2000) Anatomical variations in the pattern of the right hepatic veins: possibilities for type classification. J Anat, 197 (Part 3): 487-493.

5. Debbaut C, Monbaliu D, Casteleyn C, Cornillie P, Van Loo D, Masschaele B, Pirenne J, Simoens P, Van Hoorebeke L, Segers P (2011) From vascular corrosion cast to electrical analog model for the study of human liver hemodynamics and perfusion. IEEE Trans Biomed Eng, 58: 25-35.

6. Debbaut C, Segers P, Cornillie P, Casteleyn C, Dierick M, Laleman W, Monbaliu D (2014) Analyzing the human liver vascular architecture by combining vascular corrosion casting and micro-CT scanning: a feasibility study. J Anat, 224: 509-517. doi: 10.1111/joa.12156.

7. Debbaut C, Vierendeels J, Casteleyn C, Cornillie P, Van Loo D, Simoens P, Van Hoorebeke L, Monbaliu D, Segers P (2012) Perfusion characteristics of the human hepatic microcirculation based on three-dimensional reconstructions and computational fluid dynamic analysis. J Biomech Eng, 134: 011003 . doi: 10.1115/1.4005545.

8. Elias H, Popper H (1955) Venous distribution in livers; comparison in man and experimental animals and application to the morphogenesis of cirrhosis. AMA Arch Pathol, 59: 332-340.

9. Fondevila C, Hessheimer AJ, Taurá P, Sánchez O, Calatayud D, de Riva N, Muñoz J, Fuster J, Rimola A, García-Valdecasas JC (2010) Portal hyperperfusion: mechanism of injury and stimulus for regeneration in porcine small-for-size transplantation. Liver Transpl, 16: 364-374.

10. Gaudio E, Onori P, Pannarale L, Alvaro D (1996) Hepatic microcirculation and peribiliary plexus in experimental biliary cirrhosis: a morphological study. Gastroenterology, 111: 1118-1124.

11. Haenssgen K, Makanya AN, Djonov V (2014) Casting materials and their application in research and teaching. Microsc Microanal, 20: 493-513. doi: 10.1017/ S1431927613014050.

12. Hodžić A, Zuko A, Avdić R, Alić A, Omeragić J, Jažić A (2013) Influence of fasciola hepatica on serum biochemical parameters and vascular and biliary system of sheep liver. Iran J Parasitol, 8: 92-98.

13. Kachlik D, Baca V, Stingl J (2010) The spatial arrangement of the human large intestinal wall blood circulation. J Anat, 216: 335-343. doi: 10.1111/j.1469-7580.2009.01199.x.

14. Kahn D, Hickman R, Terblanche J, von Sommoggy S (1988) Partial hepatectomy and liver regeneration in pigs--the response to different resection sizes. J Surg Res, 45: 176-180.

15. Kessel GK, Kardon RH (1979) Tissue and organs in SEM. WH Freeman and Company, USA.

16. Kondo S, Suzuki R, Yamazaki K, Aihara K (1993) Application of corrosion cast method for scanning electron microscopic observation of mouse embryo vasculature. J Electron Microsc (Tokyo), 42: 14-23.

17. Konerding MA, Miodonski AJ, Lametschwandtner A (1995) Microvascular corrosion casting in the study of tumor vascularity: a review. Scanning Microsc, 9: 1233-1243.

18. Kralickova A, Eberlova L, Kalusova K, Gregor T, Kochova $P$, Liska V, Kralickova M, Tonar Z (2014) Quantification of liver microcirculation using $\mathrm{X}$-ray microtomography of vascular corrosion casts. Key Engineering Materials, 592-593: 505-508.

19. Kubikova T, Witter K, Liska V, Tonar Z (2014) Morphometry and reconstruction of hepatic lobules in pig based on serial histological sections. In: Fuis V ed. University of Technology, Engineering Mechanics, Brno, pp. 340-343.

20. Lametschwandtner A, Lametschwandtner U, Weiger $T$ (1990) Scanning electron microscopy of vascular corrosion casts: technique and applications: updated review. Scanning Microsc, 4: 889-940.

21. Lametschwandtner $A$, Miodonski A, Simonsberger $P$ (1980) On the prevention of specimen charging in scanning electron microscopy of vascular corrosion casts by attaching conductive bridges. Mikroskopie, 36: 270-273.

22. Le Couteur DG, Warren A, Cogger VC, Smedsrød B, Sørensen KK, De Cabo R, Fraser R, McCuskey RS (2008) Old age and the hepatic sinusoid. Anat Rec (Hoboken), 291: 661-671. doi: 10.1002/ar.20663.

23. Lehmann KS, Ritz JP, Valdeig S, Schenk A, Holmer C, Peitgen HO, Buhr HJ, Frericks BB (2008) Portal vein segmentation of a 3D-planning system for liver surgery: in vivo evaluation in a porcine model. Ann Surg Oncol, 15: 1899-1907. doi: 10.1245/s10434-008-9934-x.

24. Masset A, Staszyk C, Gasse H (2006) The blood vessel system in the periodontal ligament of the equine cheek teeth.Part l: The spatial arrangement in layers. Ann Anat, 188: 529-533.

25. McCuskey RS (2000) Morphological mechanisms for regulating blood flow through hepatic sinusoids. Liver, 20: 3-7.

26. Mogicato G, Vautravers G, Meynaud-Collard P, Deviers A, Sautet J (2015) Blood flows in tributaries of the portal vein: anatomical and angiographic studies in normal beagle dogs. Anat Histol Embryol, 44: 460-467. doi: 10.1111/ahe.12161.

27. Motta PM, Murakami T, Fujita H (1992) Scanning electon micrscopy of vascular casts: methods and appilcations. Kluwer Academic Publishers, Boston.

28. Ohtani O, Murakami T, Jones AL (1982) Microcirculation of the liver, with spacial reference to the peribiliary portal system. In: Motta PM et DiDio UA ed. Basic and clinical hepatology. Martinus Nijhoff Publishers, The Hague, Boston, London, pp. 85-96.

29. Schwen LO, Preusser T (2012) Analysis and algorithmic generation of hepatic vascular systems. Int J Hepatol, 2012: 357687. doi: 10.1155/2012/357687.

30. Shirai W, Sato T, Shibuya H, Naito K, Tsukise A (2005) Three-dimensional vasculature of the bovine liver. Anat Histol Embryol, 34: 354-363.

31. Tonar Z, Eberlova L, Polivka J, Daum O, Witter K, Kralickova A, Gregor T, Nedorost L, Kochova P, Rohan E, Kalusova K, Palek R, Skala M, Glanc D, Kralickova M, Liska V (2012) Stereological methods for quantitative assessment of hepatic microcirculation. In: Méndez-Villas A. Current Microscopy Contributions to Advences in Science and Technology. Formatex Research Centre, Badajoz, Spain, pp. 737-748.

32. Uršič M, Vrecl M, Fazarinc G (2014) Corrosion cast study of the canine hepatic veins. Folia Morphol, 73: 475-481. doi: 10.5603/FM.2014.0071.

33. Zhu J, Chen C, Yang B, Guo Y, Ai H, Ren J, Peng Z, Tu Z, Yang X, Meng Q, Friend S, Huang L (2015) A systems genetics study of swine illustrates mechanisms underlying human phenotypic traits. BMC Genomics,16: 88. doi: 10.1186/ /s12864-015-1240-y. 